\title{
Sensitivity Enhancing of Oil Viscosity Sensor Based on Optical Fiber by Using Bending Angle Method
}

\author{
Muhammad Yunus ${ }^{1, *, a}$, A. Arifin ${ }^{2, b}$, Nurul Fuadi $^{3, c}$, A. Muhammad Syafar ${ }^{4, d}$ \\ ${ }^{1}$ Department of Physics, FMIPA, State University of Gorontalo, Jl. Prof. B. J. Habibie, Bone Bolango, 96554 Indonesia \\ ${ }^{2}$ Department of Physics, FMIPA, Hasanuddin University, Jl. Perintis Kemerdekaan KM 10, Makassar, 90245 Indonesia \\ ${ }^{3}$ Department of Physics, Faculty of Science and Technology, State Islamic University of Alauddin Makassar, Jl. Sultan \\ Alauddin No. 63 Romangpolong, Gowa, 92113 Indonesia \\ ${ }^{4}$ Department of Informatics Engineering, Faculty of Science and Technology, State Islamic University of Alauddin \\ Makassar, Jl. Sultan Alauddin No. 63 Romangpolong, Gowa, 92113 Indonesia \\ *,a yunusmuhammad0808@ gmail.com (Corresponding Author), ${ }^{\mathrm{b}}$ arifinpide@ gmail.com, c nurul.fuadi@uin-alauddin.ac.id, \\ d andi.syafar@uin-alauddin.ac.id
}

\begin{abstract}
Testing of oil viscosity sensor based on plastic optical fiber by using bending angle method is conducted to enhance the sensor sensitivity. This sensor is made by forming an optical fiber bending angle and dipped into the oil viscosity liquid. The light transmitted through the optical fiber will be received by the photodetector and the measurement results are displayed on the OPM in the form of output power. The best measurement obtained at the bending angle of $30^{\circ}$ with value of sensor sensitivity of $1.013 \mathrm{nW} / \mathrm{mPa}$.s. This method has the advantage of high sensitivity in a simple measurement process.
\end{abstract}

Keywords-Oil viscosity; optical fiber; sensor

\section{Introduction}

The growing use of optical fiber technology has a good impact on sensor applications in various monitoring fields. The application of optical fiber sensors can effectively improve vital sign monitoring and infrastructure maintenance [1], [2]. Optical fiber technology has provided innovative and efficient solutions for complex monitoring. Optical fiber has advantages such as distributed monitoring, good cable durability, long-term stability and reliable response [3].

Optical fiber works to transmit information through the medium of light. There are two types of optical fiber, namely glass and plastic optical fibers. Plastic optical fiber is stronger and more durable than glass optical fiber [4]. Fiber optic sensors have been widely used for measurements such as measurement of solution density and temperature [5], [6], monitoring volatile organic compound (VOC) gas and liquid level [7], [8], oil viscosity [9], etc.

Research about sensor based on plastic optical fiber for measuring oil viscosity has been developed in application of sensor based on temperature change. This sensor is used to measure the oil viscosity on the extrinsic system design using the back scattering method. The back scattering method was then developed to measure the oil viscosity on the intrinsic system design in sensor sensitivity testing. This method has weaknesses such as a complicated measurement process and low sensor sensitivity [10], [11]. Thus, research will be developed on sensor sensitivity testing in measuring the oil viscosity level based on plastic optical fiber by using the bending angle variation method. The bending of sensor greatly affects to the power losses that occur in the optical fiber. The greater the power losses that occur, the sensitivity of the resulting sensor enhance. This research is expected to be able to produce high sensor sensitivity in a simple measurement process.

\section{Research Methodology}

This research uses an infrared LED light source type IF-E91A which is transmitted through a step index type plastic optical fiber made of polymethyl methacrylate (PMMA). This type of optical fiber has a core $0.98 \mathrm{~mm}$, 
cladding $1 \mathrm{~mm}$, and coat $2.2 \mathrm{~mm}$. The transmitted light is then received by the photodetector type S120C with a wavelength of $400-1100 \mathrm{~nm}$. The photodetector is connected to an OPM (Optical Power Meter) type Thorlabs PM100D to display the sensor output power. Oil viscosity samples were measured by using a viscometer consisting of 10 types of samples that have viscosity variations between 270-350 mPa.s from various types of Mesran SAE 20W-40 and 20W-50 oil blends. The design of the oil viscosity sensor can be seen in Figure 1.

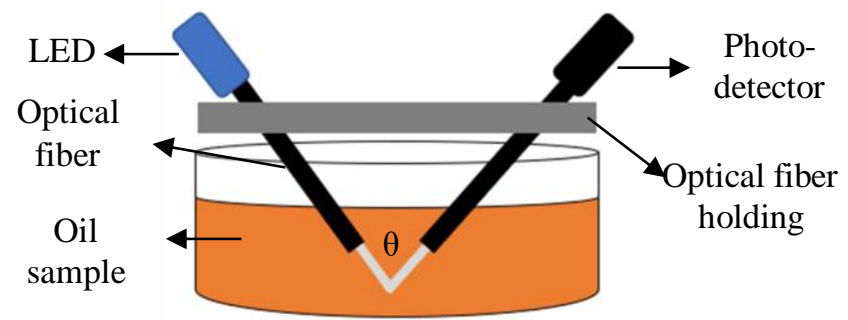

Figure 1. Design of oil viscosity sensor based on optical fiber by using bending angle variation.

Figure 1 shows design of sensor based on optical fiber. The coat of optical fiber peeled and then it is bent with several variations. Sensor is dipped into the oil viscosity liquid. The output power of sensor displayed on the OPM is then analyzed to determine the value of the sensor characteristics by using the equations of range (1), sensitivity (2), and resolution (3) below [11]:

$$
\begin{aligned}
& \Delta P=P_{\max }-P_{\text {min }} \\
& S=\frac{P_{\max }-P_{\min }}{K_{\max }-K_{\min }} \\
& R=\frac{N}{S}
\end{aligned}
$$

Where, $\Delta P$ is range of the output power, $S$ is sensitivity of sensor, $R$ is resolution, $K$ is oil viscosity, and $N$ is the smallest scale value for OPM of $0.001 \mu \mathrm{W}$.

\section{Results and Discussion}

Testing of the plastic fiber optic sensor for measuring the oil viscosity level was carried out using variations in the peel length of sensor, namely $0.5 \mathrm{~cm}, 1 \mathrm{~cm}$, and 1.5 $\mathrm{cm}$. This testing uses constant bending angle of $90^{\circ}$. The results of these measurements can be seen in Figure 2.

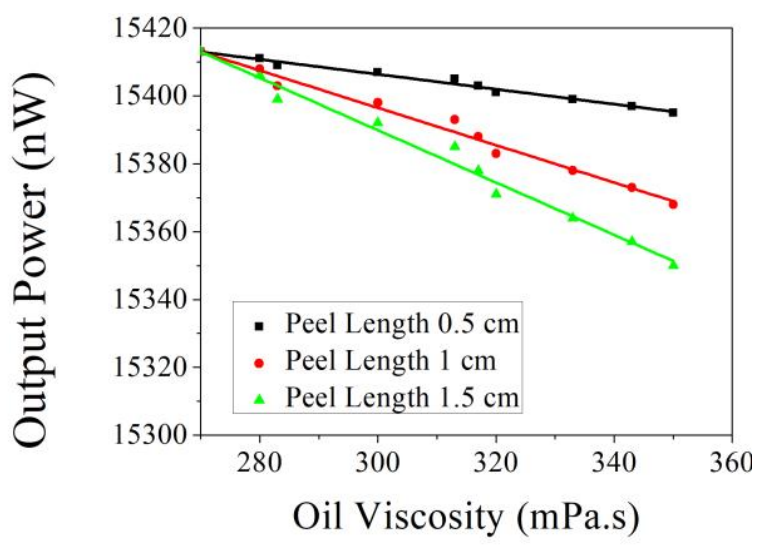

Figure 2. Graph of the output power of sensor on the peel length variation

Based on the graph, Figure 2 shows that the sensor output power decreases with increasing oil viscosity. Increasing the viscosity of the oil causes the refractive index of liquid increases, so that the output power decreases. In addition, the peel length of sensor greatly influences from the measured output power value. The value of light intensity received by the photodetector decreases with the increasing in the peel length of sensor. The smaller of the measured light intensity, the power losses increase. The biggest power losses can be seen in the type peel length of $1.5 \mathrm{~cm}$.

The data from the measurement of oil viscosity level on the peel length variation of sensor were analyzed by using equations (1), (2), and (3) can be seen in Table 1.

Table 1. Characteristics of sensor on peel length variation

\begin{tabular}{|c|c|c|c|}
\hline \multirow{2}{*}{$\begin{array}{c}\text { Characteristics of } \\
\text { Sensors }\end{array}$} & \multicolumn{3}{|c|}{ Peel Length $(\mathbf{c m})$} \\
\cline { 2 - 4 } & $\mathbf{0 . 5}$ & $\mathbf{1}$ & $\mathbf{1 . 5}$ \\
\hline Range (nW) & 18.000 & 45.000 & 63.000 \\
\hline Sensitivity (nW/mPa.s) & 0.225 & 0.563 & 0.788 \\
\hline Resolution (mPa.s) & 4.444 & 1.778 & 1.270 \\
\hline
\end{tabular}

Table 1 shows that the sensor characterization value is influenced by the sensor peel length. The sensor peel 
length increased causes the range and sensitivity of the sensor increases. Sensitivity of sensor increases causes resolution of sensor decreases. Increasing of sensor sensitivity caused by the increasing of losses power [12]. The best sensitivity sensor from the sensor peel length is shown at a peel length of $1.5 \mathrm{~cm}$ with a value of 0.788 nW/mPa.s.

Furthermore, sensor testing was carried out using constant peel length of $1.5 \mathrm{~cm}$ with the sensor bending angle variation of $30^{\circ}, 60^{\circ}$, and $90^{\circ}$ shown in Figure 3.

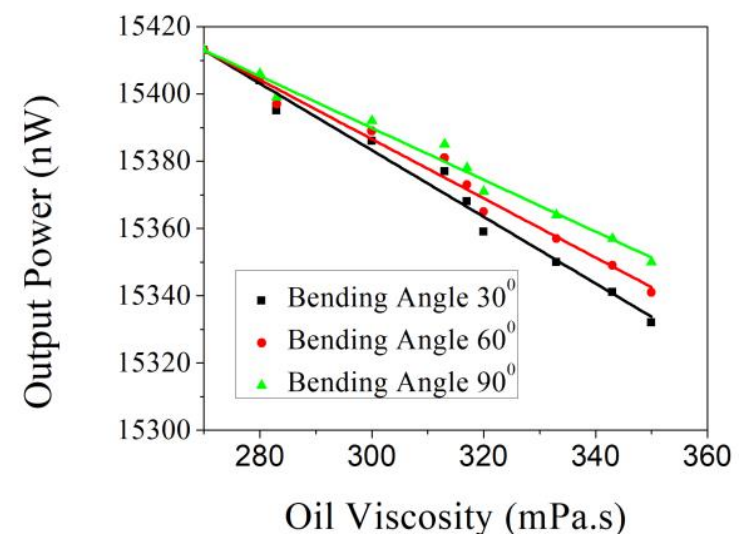

Figure 3. Graph of the output power of sensor on the bending angle variation.

The graph in Figure 3 shows the value of the sensor output power decreases when the smaller bending angle. Decreasing of the bending angle causes the losses power increases, therefore, light intensity received by photodetector decreases. The biggest losses power can be seen at type bending angle of $30^{\circ}$. The data of oil viscosity measurement result using bending angle variation analyzed by using equations (1), (2), and (3) shown at the Table 2.

Tabel 2. Characteristics of sensor on bending angle variation

\begin{tabular}{|c|c|c|c|}
\hline \multirow{2}{*}{$\begin{array}{c}\text { Characteristics of } \\
\text { Sensors }\end{array}$} & \multicolumn{3}{|c|}{ Bending Angle (') } \\
\cline { 2 - 4 } & $\mathbf{3 0}$ & $\mathbf{6 0}$ & $\mathbf{9 0}$ \\
\hline Range (nW) & 81.000 & 72.000 & 63.000 \\
\hline Sensitivity (nW/mPa.s) & 1.013 & 0.900 & 0.788 \\
\hline Resolution (mPa.s) & 0.988 & 1.111 & 1.270 \\
\hline
\end{tabular}

Characteristic values of sensor shown at Table 2 influenced by bending angle of sensor. Sensitivity of sensor increases caused the smaller bending angle. Sensors that are getting bent cause the losses power increases, so that the sensitivity of sensor increases [12]. The best sensitivity showed at bending angle of $30^{\circ}$ is $1.013 \mathrm{nW} / \mathrm{mPa}$.s. The result of this research has sensitivity value more enhance compared to previous research by using back scattering method of 0.205 nW/mPa.s [11]. The advantage this method is high sensitivity in the simple measurement process.

\section{Conclusion}

The output power of sensor influenced by peel length of optical fiber sensor. Increasing peel length cause the losses power increases, so that the output power decreases. Likewise with the bending angle decreases causes the losses power increases, so that the output power decreases. Enhancing of the losses power based on plastic optical fiber sensor cause the sensitivity enhances. The best sensitivity in the oil viscosity measurement showed at the bending angle of $30^{\circ}$ is $1.013 \mathrm{nW} / \mathrm{mPa} . \mathrm{s}$.

\section{References}

[1] A. Arifin, Kasmiah, M. Yunus, S. Dewang, B. Abdullah, and D. Tahir, "Analysis characteristics embedded plastic optical fiber sensors for crack detection in concrete structures," IOP Conf. Ser. Earth Environ. Sci., Vol. 235, No. 1, 2019, doi: 10.1088/1755-1315/235/1/012013.

[2] C. Perezcampos Mayoral et al., "Fiber Optic Sensors for Vital Signs Monitoring. A Review of Its Practicality in the Health Field," Biosensors, Vol. 11, No. 2, 2021, doi: 10.3390/bios 11020058 .

[3] M. A. Caponero, "Special issue 'fibre optic sensors for structural and geotechnical monitoring," Sensors (Switzerland), Vol. 20, No. 8, 2020, doi: 10.3390/s20082415.

[4] A. Arifin, Hardianti, M. Yunus, and S. Dewang, "Application of plastic optical fiber material as $\mathrm{pH}$ measurement sensor using loop configuration," J. Phys. Conf. Ser., Vol. 1317, No. 1, 2019, doi: 10.1088/1742-6596/1317/1/012047.

[5] S. K. Idris, H. Haroon, H. Abdul Razak, and A. S. Mohd Zain, "Investigation on fiber optic sensor using FBG for various temperature and liquid density," J. Phys. Conf. Ser., Vol. 1502, No. 1, 2020, doi: 10.1088/1742-6596/1502/1/012009.

[6] I. Yulianti et al., "Characterization of Temperature Response of Asymmetric Tapered-Plastic Optical Fiber-Mach Zehnder Interferometer," J. Penelit. Fis. dan Apl., Vol. 10, No. 1, p. 34, 2020, doi: 10.26740/jpfa.v10n1.p34-43. 
[7] Y. Yang et al., "Optical fiber sensor based on a cholesteric liquid crystal film for mixed VOC sensing," Opt. Express, Vol. 28, No. 21, p. 31872, 2020, doi: 10.1364/oe.405627.

[8] Y. Zhang et al., "An Optical Fiber Liquid Level Sensor Based on Side Coupling Induction Technology," J. Sensors, Vol. 2018, 2018, doi: 10.1155/2018/2953807.

[9] B. Abdullah, M. Yunus, and A. Arifin, "Analysis effect of temperature changes on measurement of oil viscosity based on plastic optical fibres sensor and microcontroller," J. Phys. Conf. Ser., Vol. 1242, No. 1, 2019, doi: 10.1088/17426596/1242/1/012024.

[10] A. Anggita and H. -, “Aplikasi Serat Optik Sebagai Sensor Kekentalan Oli Mesran Sae 20W-50 Berbasis Perubahan Temperatur", (Application of Fiber Optic as a Viscosity Sensor for Mesran Sae 20W-50 Oil Based on Temperature Changes), J. Fis. Unand, Vol. 4, No. 3, pp. 239-246, 2015, doi: 10.25077/jfu.4.3.

[11] M. Yunus and A. Arifin, "Karakterisasi Sensor Kekentalan Oli Berbasis Serat Optik Plastik Menggunakan Metode Back Scattering", (Characterization of Oil Viscosity Sensor Based on Plastic Optical Fiber Using Back Scattering Method), Positron, Vol. 8, No. 1, p. 31, 2018, doi: 10.26418/positron.v8i1.24108.

[12] A. Arifin, I. Irwan, B. Abdullah, and D. Tahir, "Design of sensor water turbidity based on polymer optical fiber," Proc. 2017 Int. Semin. Sensor, Instrumentation, Meas. Metrol. Innov. Adv. Compet. Nation, ISSIMM 2017, Vol. 2017-January, pp. 146-149, 2017, doi: 10.1109/ISSIMM.2017.8124280. 